Estudios 



\title{
La Villa de Almonte y el convento de Morañina*
}

\author{
Josefa González Clemente \\ ARCHIVO MUNICIPAL DE BOLLULLOS DEL CONDADO \\ pepacecilia@gmail.com
}

Fecha de recepción: octubre 2017

Fecha de aceptación: diciembre 2017

\section{Resumen \\ Este artículo forma parte de una investigación en curso, sobre la historia del monasterio del Señor San Juan Bautista de Morañina, de la Tercera Orden Regular de Penitencia de San Francisco. Tiene como objetivo probar la relación existente entre la villa de Almonte y el citado monasterio a lo largo de toda su historia, aunque la mayor parte de los documentos aportados pertenecen al s. XVII, por los acontecimientos decisivos que entonces tuvieron lugar.}

Palabras Clave

Convento de San Juan de Morañina; Tercera Orden Franciscana; Duque de Medina Sidonia; Villa de Almonte; Concejo. Enfermería. Capellanía de Doñana; S. XVII.
Abstract

This article is part of an ongoing research about the history behind the Lord's monastery San Juan de Morañina, from the Tercera Orden Regular de Penitencia de San Francisco-Third Regular Order of Penance of St. Francis. It aims to demonstrate the connection between the town of Almonte and the mentioned monastery throughout its entire history, although the majority of the documents provided date back to the $17^{\text {th }}$ century due to the crucial events that took place at the time.

KEY WORDS

Convent of San Juan de Morañina; Franciscan Third Order; Duke of Medina Sidonia; Town of Almonte; Council. Infirmary; Chaplaincy of Doñana; 17th century.

San Juan de Morañina fue construido extramuros de la villa de Bollullos del Condado, en el camino que, cercano a la costa y a través de Almonte, comunicaba las tierras de Huelva pertenecientes a la casa de Medina Sidonia con Sanlúcar de Barrameda, en Cádiz.

Se fundó en el año 1400, por voluntad del entonces Arzobispo de Sevilla Don Gonzalo de Mena y Roelas, cuando queriendo construir una Cartuja en la citada ciudad y habiendo encontrado el lugar idóneo, ofreció a los franciscanos Terceros que desde unos años antes el mismo había establecido en esa zona, la iglesia de San Juan de Aznalfarache, cercana a la capital y la ermita de San Juan de Morañina, en término de Bollullos.

\footnotetext{
* Este artículo forma parte de una investigación en curso, sobre la historia del monasterio del Señor San Juan Bautista de Morañina, de la Tercera Orden Regular de Penitencia de San Francisco. Y tiene como objetivo constatar y resaltar la relación existente entre la villa de Almonte y el citado monasterio, a lo largo de toda su historia, aunque la mayor parte de los documentos aportados pertenecen al s. XVII, por los acontecimientos decisivos que entonces tuvieron lugar.
} 
Desde el momento de la fundación, el monasterio estuvo bajo la protección del segundo conde de Niebla, que lo dotó con el cortijo de Los Villares y la dehesa de Montañina. En su iglesia se veneró una antigua y bella imagen de Santa María de origen incierto. Durante los s. XV y XVI, los Terceros fomentan la devoción por esta imagen y Morañina se convierte en el principal centro de devoción mariana de una zona que se extendía y sobrepasaba los pueblos limítrofes del Condado.

Pero no todos son parabienes en nuestro convento. En la segunda mitad del s. XVI, tienen lugar acontecimientos en la Orden de Penitencia, (intento de extinción a instancias del rey Felipe II,) que afectan a todas sus casas y miembros en España. Cuando la tormenta pasa, la Orden está seriamente mermada y no es hasta final de siglo cuando empieza la recuperación.

En 1602, la comunidad de Morañina abandona su casa conventual. Se llevan consigo la Imagen de la Virgen, objetos litúrgicos y toda clase de enseres que les puedan ser útiles. No se olvidan ni la campana que con su son, marcaba la vida de los religiosos. Su destino era Sevilla, la ciudad donde fundaron una nueva casa, el convento de Nuestra Señora de Consolación, en la collación de Santa Catalina.

Los vecinos de Bollullos quedan desolados, especialmente, por la pérdida de la Imagen objeto de su devoción. Pero todos los intentos por recuperarla fracasan. La relación entre los habitantes de la villa y los frailes de penitencia pasa por sus peores momentos. A partir de estos acontecimientos, intentaremos probar la estrecha relación entre la villa de Almonte y nuestro convento que, aunque a lo largo de toda su existencia fue una realidad, se van a ver reforzada en esta etapa, por los distintos aconteceres que van a tener lugar.

\section{La RELACión CON LOS VECINOS DE Almonte.}

¿Quedó desierto el monasterio tras la marcha de sus moradores? No por mucho tiempo. Ese mismo año, en octubre de 1602, la nueva comunidad empieza a rentabilizar las antaño propiedades de Morañina. Los frailes del nuevo convento de Consolación, en escritura firmada ante Pedro Almonacid, dan a tributo de por vida, al Ldo. Martín Morales Cervellón, médico y a Dña. María de Galindo, su mujer, vecinos de Almonte:

"una heredad con su casa de habitación y morada y aposento alto e bajo e una huerta dentro de ella con 269 pinos y 45 almendros y 18 higueras y 84 alcornoques y encinas y 214 pies de olivos". (1)

La heredad, con la huerta y demás propiedades, eran las tierras que habían sido propiedad de Morañina; la casa descrita, el antiguo monasterio y el precio a pagar por todo ello, 200 reales anuales. Pero el contrato de arrendamiento tuvo corta vida. Hemos podido leer en la escritura de rescisión del mismo, (2) (vid. Apéndice Documental, n 1 y 2) como el ministro de Consolación de Sevilla, fray Joan Falcón, con poder de su comunidad, ante los malos usos de los arrendatarios "que talan árboles y venden materiales" y para evitar un pleito, pactan un acuerdo en virtud del cual, en octubre de ese mismo año cancelan el arrendamiento.

El 5 de agosto de 1603, (3) en el convento de Consolación de Sevilla, las propiedades anteriormente citadas, (no se incluye la que fue casa convento) fueron vendidas a 
Juan Pinto, clérigo presbítero, vecino de Almonte y depositario de los fondos de la recién constituida Capellanía de Misas en la ermita de la entonces Nuestra Señora de Las Rocinas, por parte del indiano Baltasar Tercero.

Finalmente, cuatro meses después y en la villa de Almonte (4), las propiedades adquiridas por el clérigo almonteño fueron vendidas al Concejo de Bollullos. No sabemos la razón por la cual las autoridades de esta villa se hicieron con las antiguas propiedades de Morañina. Las actas capitulares que nos podían poner sobre la pista fueron destruidas pero, no creemos que la compra del Concejo fuese, como opinan algunos, por presión de los Terceros. Creemos por el contrario, que los frailes de la Orden, en los momentos que ocurren los hechos citados, no piensan en volver a Bollullos. De hecho, se están deshaciendo de algunas propiedades. Lo prueba la mencionada venta de las tierras que pasó luego a poder de los bollulleros, que no fueron las únicas de las que se deshicieron.

Es por ello que el 4 de enero de 1604, (5) Pedro Bejarano, vecino de Almonte, hace dejación del arrendamiento de 30 pies de olivos al pago de El Pinillo de La Jabonera y otras tierras en el término de Almonte, antiguas propiedades de Morañina, y que según dice la escritura, los frailes de Sevilla no pueden venir a cobrar su rentas y prefieren vender. El 15 de enero de 1604, (6) fue vendida la tierra anteriormente citada por 30 ducados a Francisco Hernández Pichardo, vecino de Almonte y Familiar del Santo Oficio.

\section{Refundacion de San Juan de Morañina.}

En mayo de 1606, se convocó en Toledo el capítulo general de los Menores Observantes de San Francisco. A él acuden en representación de la Orden de Penitencia, su procurador, fray Juan de Gama y fray Ivo de Jesús, ministro del monasterio de Granada. Ambos solicitan y logran para los terceros andaluces la creación de una provincia independiente, aunque siga bajo el control del ministro General de la Observancia. Los Terceros logran su objetivo y la nueva provincia se llamará del Arcángel San Miguel de Andalucía y reino de Granada. El Padre fray Ivo de Jesús fue designado como primer provincial.

A partir de este momento, los Terceros cobrar nuevos bríos y deciden abrir de nuevo la casa convento de Bollullos. Para ello, el provincial, fray Ivo y el nuevo ministro de Morañina, fray Francisco López, solicitan la ayuda del duque de Medina Sidonia como protector del convento. Su Excelencia desde Sanlúcar, escribe a los cabildos de la zona comunicándoles que sería muy de su agrado que contribuyesen generosamente a tan grande obra. Y a su vez, indica al concejo de Bollullos que:

"les hiciese limosna de bolberles el cercado que ansi tenian comprado del dicho Joan Pinto, que era del dicho monasterio, por quanto querian volver a reedificar la casa del señor San Joan que ansi avian dejado y desamparado”. (7)

El concejo de Bollullos accede a la petición por escritura firmada el 5 de junio 1607, (8) con la condición de que la campana y la imagen de la Virgen vuelvan a la villa de Bollullos para el día de San Juan de ese mismo año. Los frailes no cumplen lo pactado y el concejo pone pleito a los Terceros.

Unos meses antes, en Almonte, fray Ivo de Jesús se dirige a su concejo manifestando que el cercano convento de Morañina esta desmantelado e inhabitable, que la Orden lo 
quiere reformar por voluntad de Dios y es imprescindible la ayuda de esta villa y lugares comarcanos y para ello, piden al cabildo que acudan con alguna limosna para la reedificación del citado convento, a la cual acceden:

"Visto en este cabildo fue acordado se le de de limosna al dicho convento por tiempo de tres años, en cada uno de ellos cinquenta ducados, que son ciento y y cinquenta ducados, como vayan labrando con tanto que se dé cuenta de ello al Conde mi señor, y se le escriba pidiendo licencia para se los poder dar". (9)

Unos meses más tarde, hay nuevas aportaciones de Almonte para reconstruir Morañina. Esta vez la iniciativa parte de un grupo de vecinos almonteños que se dirigen al Cabildo con una petición al Conde para hacer:

"merced e limosna a los frayles del convento de San Juan de Morañina del rebusco de las heredades y su Excelencia lo permitió a este cabildo, por tanto acordaron e mandaron que se entienda de venderse los rebuscos de las heredades de aquellas personas contenidas en dicha petición y tienen firmado en ella, y ansi lo acordaron". (10)

La reconstrucción del convento se prolonga durante muchos años. Su comunidad estaba sujeta a los avatares de la Orden en la Provincia de San Miguel de Andalucía y reino de Granada a la que pertenecía. De todos los problemas a los que se enfrentaba la Nueva Provincia, fue uno especialmente costoso. Nos referimos al conflicto con la Orden de los Mínimos. Los frailes de la Orden fundada por San Francisco de Paula pensaban que el hábito de los Terceros era tan parecido al suyo que se prestaba a confusión de los miembros de ambas órdenes. Ellos pretenden que todos los hermanos de Penitencia cambien de forma de vestir y para ello no dudan en acudir a Roma en 1607. El conflicto dura hasta 1610, cuando los Terceros se ven obligados a cambiar de hábito y emplear para ello nada menos que ocho mil escudos.

No termina aquí el problema con la vestimenta de la Orden de Penitencia pero, a falta de otros datos, queríamos justificar de algún modo la prolongación de la reconstrucción del convento extramuros de Bollullos. El motivo, la falta de fondos. Aunque quizás bastaría mencionar que nuestra casa convento estaba rodeada de poblaciones pequeñas que no destacaban por su riqueza; antes al contrario. En cuanto a las rentas del convento eran más que suficientes para mantener una comunidad pequeña pero harto insuficiente para la reconstrucción de su casa.

\section{El concejo de Almonte.}

La villa de Almonte mientras tanto, sigue ayudando a los Terceros. En febrero de 1608, (11) con lo que montare el rebusco de la aceituna de aquella cosecha. En diciembre de 1651, (12) tras petición hecha a instancias del duque D. Gaspar Alonso Pérez de Guzmán, le conceden 70 pinos. En otra sesión del cabildo, (13) y tras la petición del ministro fray Blas Mécora de 30 pinos, le permiten cortar 24 en el paraje de Monte de Higo, propiedad del Concejo, para reparar la enfermería de Almonte. 
En agosto de 1660 y desde Valladolid, el Duque escribe a su villa de Almonte:

“... el guardian del Convento de Morañina me da quenta que la iglesia como tan antigua se arruino y que para repararla necesita de alguna madera y que los vecinos le ayudasen con sus limosnas y siendo esta obra tan de piedad no he querido negarme a encargaros que de los pinares que tiene el cabildo le socorrais con todo lo mas que pudiereles..."

La carta se lee en sesión del cabildo del mes de septiembre, a la vez que una petición del padre fray Cristóbal de Toro Gálvez que comunicaba que para reparar la iglesia necesitaba:

"24 pinos para hacer tablas ... y una docena de palos para alfardas". (14)

El Concejo da licencia a los frailes para cortar la madera que necesitan en el sitio de Cañaveralejo.

El 30 de enero de 1673, se concede a Morañina 4 trozas para tablas para hacer unos cuartos. Con todo lo anteriormente citado, está más que justificado el documento fechado en 30 de noviembre del año 1663, (CRUZ DE FUENTES, L., 1908: 51.) (Vid. Apéndice Documental, $n^{\circ}$ ) en virtud del cual, se demuestra la protección del concejo de Almonte al Convento de Morañina. En él, fray Cristóbal del Toro Gálvez, ministro del convento, fray Joan de Toro y fray Pedro de San Antonio, dan fe que en el libro de misas del monasterio queda puesta una memoria de maitines y misa cantada en la festividad de la Natividad. De esta manera, la comunidad da gracias al Cabildo de Almonte por sus buenos aciertos para con sus religiosos. El documento citado es el único de ese tipo del que, por el momento, tenemos noticias. El original, se conserva en el Libro de Propios de esta Villa y Patronazgo de las Capellanías del Cabildo, en el Archivo Municipal de Almonte.

La huerta del CERCAdo de SAN Juan.

Gran parte de los documentos citados en este artículo provienen de los protocolos notariales de Bollullos. Uno de ellos certifica el arrendamiento de una de las propiedades más significativas del convento, su huerta, a un vecino de Almonte

Dicha huerta estaba situada dentro del cercado de San Juan, que limitaba algunas propiedades cercanas a la casa convento. Perteneció a los frailes desde su fundación y era parte importante en la economía de la casa pues, se solía arrendar no solo a cambio de dinero sino por hortalizas, frutas y verduras vitales para el sustento de toda la comunidad. Entre los documentos referentes a Morañina, en los protocolos notariales de Bollullos, las escrituras sobre los contratos referentes a la huerta son de los más numerosos.

En 1655 (15) (Vid. Apéndice Documental n 3) aparece en dichos protocolos patente dada por el Provincial de los Terceros andaluces, fray Pedro Martínez del Salto, lector jubilado y calificador del santo Oficio, dirigida al Padre fray Juan Román de Morales, ministro de Morañina. En ella, y desde el convento de San Antón Abad de Granada, le da licencia para arrendar la huerta del convento a Alonso Ruiz Bejarano, vecino de Almonte. 
A la patente le sigue la escritura de arrendamiento firmada en presencia del citado almonteño, en el convento de Morañina el 3 de junio de 1655, (16) por la cual los frailes le arriendan la propiedad por espacio de una vida y con las condiciones siguientes:

"El arrendatario ha de tener la huerta sembrada y cultivada en todas sus labores de manera que vaya en aumento ..."

$2^{\text {a }}$ Durante el tiempo del arrendamiento no se ha de poder arrendar ni traspasar sin permiso del convento.

$3^{\text {a }}$... el dicho Alonso ... ha de ser obligado a hacer a su costa las ruedas y carro y demás aderemes de la noria ...

$4^{\mathrm{a}} \ldots$ y por ningún curso de tiempo ha de poder el susodicho adquirir derecho de propiedad ...

$5^{\text {a }}$... el dicho Alonso Ruiz está obligado a plantar cada año veinte árboles frutales y si se perdieren no le ha de poder obligar este convento sino al siguiente año...

$6^{\mathrm{a}} \ldots$ que a de tener obligación precisa a dar a este convento todos los años la ortaleza que fuere necesaria para el sustento de la comunidad ... y asi mismo cebollas ajo nabos sanaorias cardos y fruta de la que diere la dicha huerta.

$7^{a} \ldots$ este convento ha de dar todos los años para el beneficio de dicha huerta todo el estiércol que hubiere en su caballería sin interés alguno.

$8^{a}$... Alonso Ruiz ha de ser obligado a limpiar y escamondar todos los pinos que están dentro de la dicha huerta y si el susodicho hubiera menester tres o cuatro asnados los pueda cortar."

Esta huerta fue desamortizada, con el resto de sus propiedades, en 1835. Salió a pública subasta en las casas consistoriales de Huelva en 1840 (17) y fue adjudicada a un vecino de Bollullos, Manuel Martín (18) por 12.000 reales. A finales de los setenta del siglo XX, la huerta fue vendida por Juan González Ojeda, mi padre, que trabajó en ella durante toda su vida. A partir de entonces, la que fuera huerta del antiguo eremitorio, dejó de existir.

\section{LA HOSPEDERIA DEL CONVENTO}

En la legislación general de la Orden de Penitencia franciscana se contempla el cuidado de los ancianos y enfermos de la misma. Cada convento debía tener una enfermería con un enfermero que cuidaba de todos los hermanos que lo necesitasen; evitándose así que fuesen curados en casa de seglares, lo cual además estaba totalmente prohibido. A la vez, estos establecimientos funcionaban como hospedería, donde se acogían a los huéspedes de los religiosos.

La hospedería del convento de Morañina en Almonte se crea a raíz de un vínculo que fundó el Licenciado Juan Ruiz Prieto, (19) abogado y vecino de Almonte. Disponía entre otros bienes, de unas casas de morada en la calle del "Serro", linde con casa de Gerónimo de Mora.

El 3 de mayo 1655, (20) el capitán Don Pedro Bejarano, alcalde ordinario de Bollullos y en ese momento patrono del vínculo, declara que es su voluntad dar las dichas casas, 
que amenazan ruina, al convento de Morañina, porque los frailes pensaban que eran capaces de obrar en ella enfermería para la curación de sus religiosos.

La comunidad de Morañina, con licencia del Provincial, (21) (Vid. Apéndice Documental $n^{\circ} 4$ ) aceptan dicha donación a tributo perpetuo, con cargo de decir sesenta misas rezadas en cada un año en el convento de las monjas de Ntra. Sra. de la Encarnación en Almonte. La aceptación por parte del convento está fechada en Morañina el 3 de junio de 1655.

A día de hoy, conocemos muy poco sobre el devenir de la enfermería hospedería, sobre los religiosos que atendió o sobre los huéspedes a los que dieron cobijo. En 1766, fue su presidente (22) el Muy Reverendo Padre fray Antonio de Santa Teresa. Citaremos además, la respuesta dada por el concejo del Almonte (23) a una petición del Duque hecha desde Madrid, referente a librar del servicio de las armas al enfermero que trabajaba en la villa para los Terceros Franciscanos. Los regidores sugieren que son los frailes quienes deben sufragar los gastos ya que, de aceptar el Concejo la petición del Duque, ocasionaría grave perjuicio a los vecinos que, como el enfermero, no podían pagar para evitar el servicio en el ejército.

En 1799, mediante patente dada por el provincial de la Orden Tercera de San Francisco, el Padre fray Bartolomé de Soria, desde el convento Madre de Dios y San Rafael, extramuros de la ciudad de Córdoba, se autoriza la venta de la antigua hospedería de Almonte.

Los frailes justifican la venta por la poca utilidad que tiene para la comunidad, al haberse trasladado la enfermería a la calle Villalba de Bollullos Par del Condado y los muchos gastos que ocasiona al año para su mantenimiento. Por si lo anteriormente citado no fuera suficiente, alegan otras razones: tienen un comprador y con el producto de la venta se puede ampliar la capacidad de la hospedería de Bollullos.

"Y comprar nuevas ropas de cama y demás menesteres de que dicha oficina tiene mucha necesidad; y que si acaso hubiere algún sobrante se pueda recompensar el todo o parte de aquel capital poniendo estacas de olivos o viñas, pues tiene la comunidad tierra suficiente para cualquier de estos plantíos.”. (24)

En la villa de Almonte, en 1800, (25) fue vendida la antigua casa hospedería por el ministro del monasterio de San Juan de Morañina, el Padre fray Isidro de San Joseph y con poder de toda su comunidad, a D. Valentín Liar, vecino de la villa de Villalba y a D. Pedro López, vecino de Almonte, con los cargos anuales de 80 reales a la Capellanía que fundó Marina del Río, 5 reales a la fábrica de la parroquia de la villa y 6 reales al mencionado convento de San Juan de Morañina.

Por esa fecha, la propiedad lindaba por un lado con casa de la viuda de Francisco de Rivas y por otro con la calle Caballeros y bodega de D. Vicente Cepeda.

\section{Trueque con el Conde de Cañete.}

Esta permuta se escrituró en Morañina en 1733, (26) estando presente D. Antonio de Ojeda, vecino de Almonte, en nombre del Sr. Conde Cañete, como administrador y mayordomo de sus bienes. Pero los acontecimientos que lo ocasionan ocurrieron años antes. 
Narra este documento notarial que el convento tenía 4 fanegas de tierra calma en término de Almonte y sitio que llaman El Cortijo, que están unidas con otras 6 fanegas en el mismo sitio que fueron de D. Joseph Pichardo y Morera, presbítero, Comisario del Santo Oficio y vecino de Almonte. El Señor Conde de Cañete tenía otras 4 fanegas de tierra calma, dentro de la cerca del convento, por la parte de abajo, junto a un horno de cocer ladrillos que perteneció a dicho Comisario. El convento y Don Joseph Pichardo intercambiaron ambas propiedades mediante permuta oral que ambos hicieron efectiva. Posteriormente, las propiedades del Comisario citadas pasan a manos de Dña. Teresa María Pichardo, su sobrina, mujer que fue del señor Conde de Cañete y por muerte de la susodicha, recayó en el hijo menor de ambos, D. Nuño Carlos de Villavicencio.

En el documento se da por buena la permuta realizada entre el convento y D. Joseph Pichardo y se escrituran las 4 fanegas sitio El Cortijo a nombre de su hijo y la 4 fanegas dentro de la cerca del convento a nombre del mismo. La pronta resolución de la permuta y las facilidades dadas por ambas partes, así como las muestras de agradecimiento, queda reflejada en el intercambio de cartas entre el conde de Cañete y el ministro del convento. (27) (Vid. Apéndice Documental, nº 6).

\section{DOÑANA Y MORAÑInA.}

En 1640, el Padre fray Juan de Salas, ministro de Morañina, da su poder a Hermenegildo de Pineda, hermano mayor del Hospital del Buen Suceso de Sevilla, para que en su nombre y en el de sus hermanos pueda recoger "un caballo mío color castaño sayno abrocado sobre el que está pleyto pendiente" (28). El dato que en este caso llamó mi atención no es tanto el motivo del documento como su encabezamiento. El ministro de Morañina se presenta como presbítero religioso de la Orden Tercera de S. Francisco, “... Capellán de Su Excelencia el Sr. Duque de Medina Sidonia en el Bosque de Doñana.”

El origen y creación de esta capellanía se remonta al año de 1613 y surge por la necesidad observada por el duque de Medina Sidonia de contar de forma permanente en aquel apartado lugar de celebración de misas en los domingos y fiestas de guardar en el calendario cristiano; recordemos que aunque espacio alejado era muy frecuentado por viajeros además del numeroso personal al servicio del Palacio e industrias del ahora conocido por Coto de Doña Ana, antiguo Bosque de Las Rocinas. En una carta de obligación otorgada en 21 de abril de 1613 ante el escribano público de Almonte, Alonso de la Parra, fray Alonso Calero, Ministro del convento de San Juan de Morañina, bajo licencia del Padre fray Francisco de Arjona, Vicario Provincial de la Provincia de Andalucía y Reino de Granada, se compromete ante Don Alonso Pérez de Guzmán El Bueno, duque de Medina Sidonia, a que un fraile del Morañina dirá misa los domingos y todos los festivos "en las Casas y Bosque de Doña Ana” por el tiempo que el Duque establezca, pagándose de limosna a dicho convento 5 reales y medio por misa y un cahíz de cebada cada año, "librándose en Pedro Martín Pichardo [Regidor del Concejo] de lo procedido de la caza de patos y conejos o de los arrendadores" (29).

Otros documentos posteriores constatan la pervivencia y posesión de esta Capellanía por parte del convento, extramuros de la villa de Bollullos Par del Condado. En 1687, (30) Don J. Antonio de Gadea, en nombre del Duque, escribe al Tesorero General del mismo para que mande al ministro y convento de San Juan de Morañina los granos que 
le pertenecen del año 1687 por "la capellanía que dicho convento sirve en las casas del bosque de Doña Ana."

En octubre del mismo año, fray Pablo de Jesús, ministro del convento, (31) dice que a finales de agosto había recibido de D. Pedro Muñoz Franco, Tesorero del Duque, "doze fanegas de trigo y doze de zevada" que se da al monasterio por la citada Capellanía.

Otras noticias en este sentido nos llegan desde Almonte en 1718. D. Joseph Manuel Barrera en carta dirigida a los Señores Contadores, con noticias varias añade:

"Pase al convento de Morañina a hablarle al Padre ministro para que fuese religioso a decir la misa a Doñana y están prontos a venir el domingo próximo.” (32).

Desde Sanlúcar, en agosto de 1718, D. Gaspar de Montalvo y Verdejo, criado del Duque, le escribe contando noticias de todo tipo y una vez más se refiere a la Capellanía de Doñana. Cuenta que han nombrado religioso para que diga las misas al Padre fray Miguel de S. Gregorio y refiere además que los Mínimos de Almonte no querían servir dicha Capellanía:

“... solo fray Lucas Millán de dicha Orden, que se halla muy enfermo, ético y con otros accidentes, quería ejercerla pero que se había de alcanzar de su prelado la licencia y que viviría en el palacio de Doña Ana, lo que tiene el inconveniente que Vs reconocerá, si muere en aquel sitio, dejando inficionado el cuarto y ornamentos y que el de San Juan de Morañina puede hacer estos viajes sin mucha incomodidad porque el convento, tiene bagajes." (33).

\section{MAlos TiEmpos. (s. XIX)}

La decadencia del convento de la Orden Tercera empieza en la segunda mitad del siglo XVIII pero no es hasta la siguiente centuria cuando todo se complica de forma definitiva. A principios del siglo XIX, José Bonaparte es rey de una España que casi en su totalidad está en poder de los franceses. Mediante Decreto Real suprime las Órdenes Religiosas y los conventos son abandonados y sus bienes expoliados. Una vez expulsados los franceses, las perspectivas a la que se enfrentan las casas conventuales son poco halagüeñas. La sociedad civil cambia de mentalidad. El Gobierno de España pasa de proteger a los religiosos a dictar leyes contra sus privilegios y los ingresos de donaciones procedentes de los fieles caen en picado. Muchos religiosos, especialmente aquellos que son sacerdotes, solicitan pasar al clero secular o detentar capellanías que generen ingresos por mínimos que sean.

En el transcurso de estos años nefastos, el 11 de abril de 1813, (34) Vid. Apéndice Documental, $\mathrm{n}^{\circ}$ 7) Juan José Lozano, natural de Almonte, presbítero de los Terceros de Penitencia, que ocupó los más altos cargos en la provincia de Andalucía de dicha Orden, solicita el puesto de capellán vacante en la iglesia del Rocío, de la capellanía fundada por Baltasar Tercero. Aunque sus méritos son sobrados, se enfrenta a varios competidores. El 4 de julio de 1813 se reúnen los miembros del ayuntamiento constitucional de la villa de Almonte para nombrar al capellán de la ermita marismeña. En la primera votación 
Juan José queda empatado con D. Alonso Acebedo, presbítero almonteño; en la segunda votación, se concede la capellanía a D. Alonso por un voto de diferencia.

El final de Morañina llegaría con la desamortización de sus bienes a partir de 1835. En Real Decreto fechado el 5 de julio de ese año, (35) se suprime este convento, junto a las dieciséis casas de religiosos existentes en la provincia de Huelva. En las Casas Consistoriales de la villa de Almonte se subastaron algunos bienes del convento de Bollullos. Nos referimos a 24 millares de viñas que salieron a subasta el domingo 18 de febrero de 1838 (36) a las 12 de la mañana o la de unas 48 fanegas de tierra que se rematan en el mismo lugar, el 15 de marzo de 1840, (37) de la cuales, cuatro de ellas estaba en término de Almonte, sitio de La Tirambola.

\section{CONCLUSIÓN.}

Los documentos citados en este artículo son solo un muestrario de los numerosos testimonios escritos que prueban la continua relación existente entre la villa de Almonte, a través de sus instituciones y sus vecinos, con el convento de San Juan Bautista de Morañina, de la Tercera Orden Regular de San Francisco, a lo largo de sus más de cuatro siglos de historia. El convento tuvo una larga e intensa existencia, pero pocos datos son conocidos por los actuales vecinos del antiguo cenobio. Espero y deseo que la publicación del contenido de estos documentos, contribuyan en cierta medida, en dar a conocer parte de su historia. 
APÉNDICE DOCUMENTAL

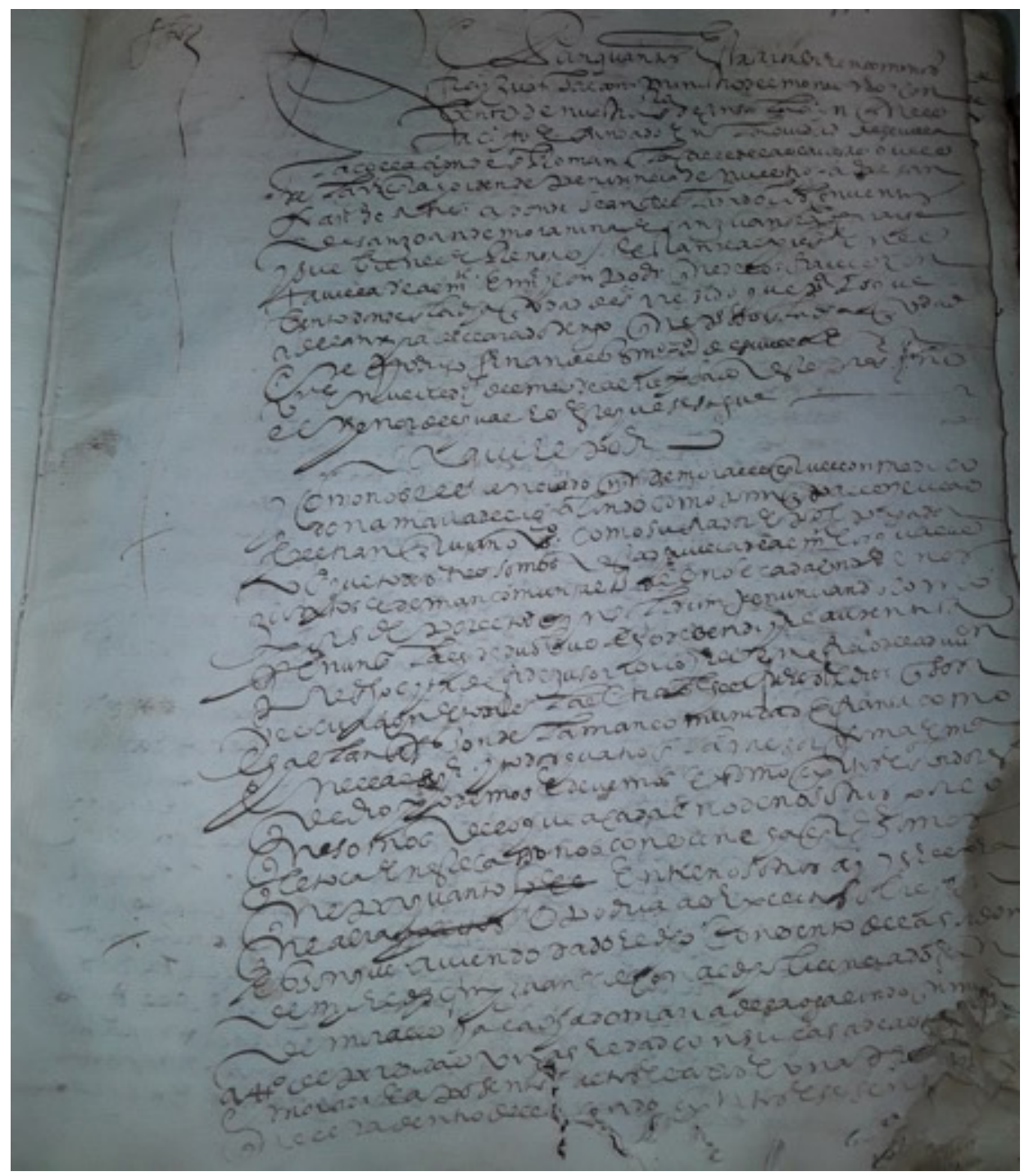

$\mathrm{N}^{\mathrm{o}}$ 1. Folio primero del contrato de rescisión del arrendamiento de la Casa convento de Bollullos y tierras anexas por parte del convento de Consolación de Sevilla, propietario de los bienes de Morañina. 


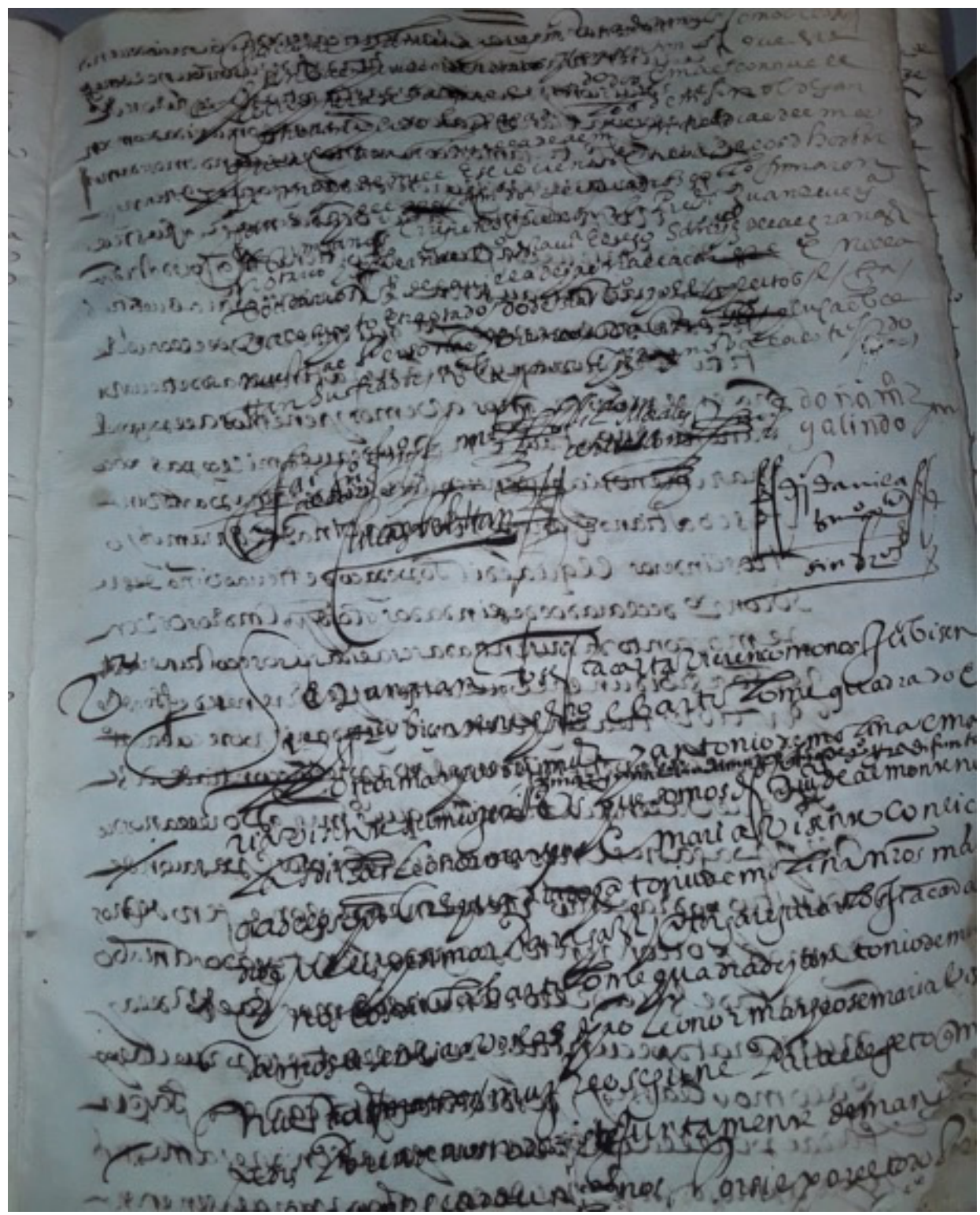

$\mathrm{N}^{\mathrm{o}}$ 2. Última página del citado contrato de rescisión. Lo firman el ministro fray Juan Falcó con poder de su comunidad de Consolación como parte arrendadora y el licenciado Don Martín Morales y su esposa Doña María de Galindo, vecinos de Almonte, que por unos meses fueron sus arrendatarios. 


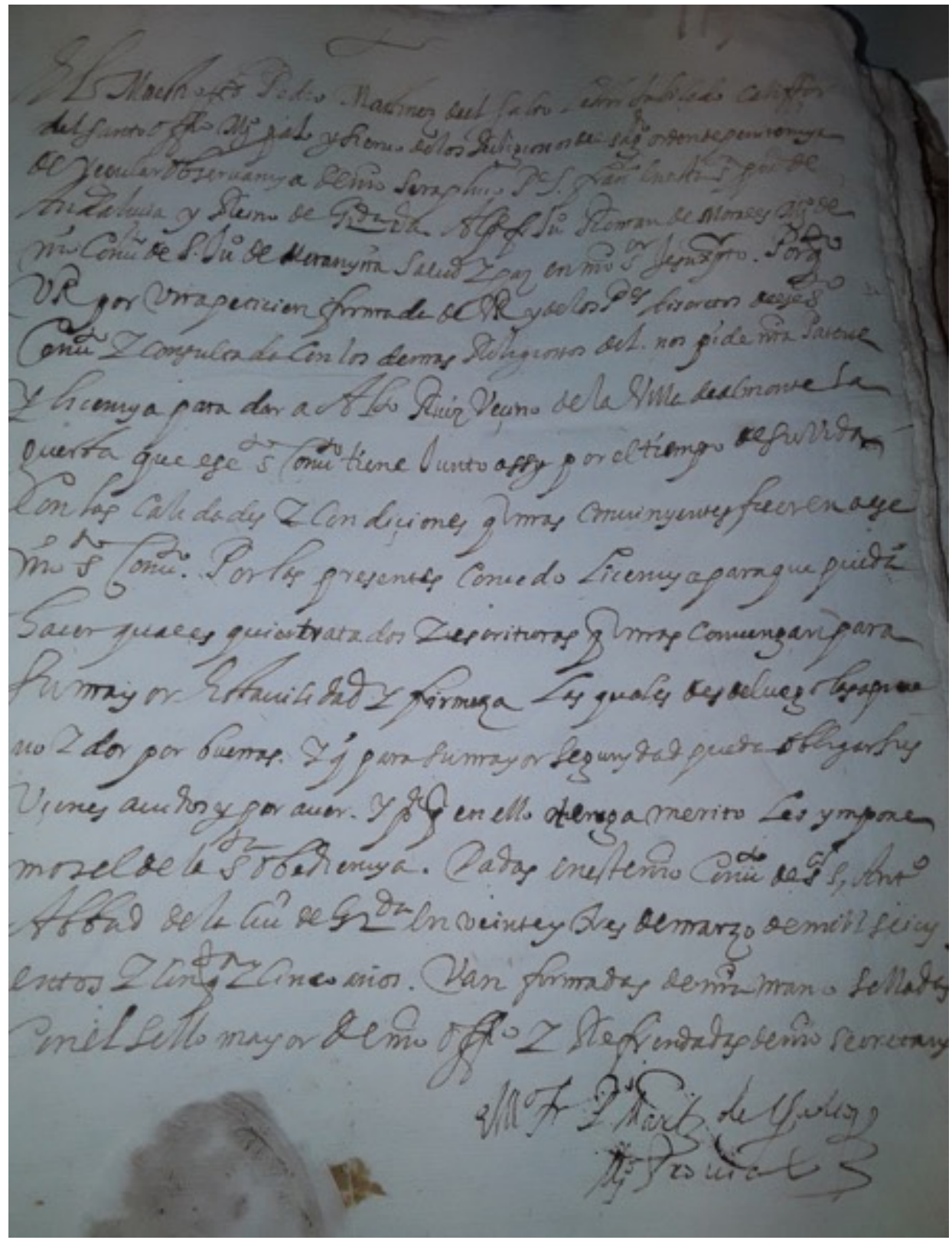

$N^{0}$ 3. El ministro de la Provincia de Terceros Franciscanos de San Miguel de Andalucía, da su licencia a la comunidad de Morañina para que arriende la huerta de su propiedad a Alonso Ruiz, vecino de Almonte. 


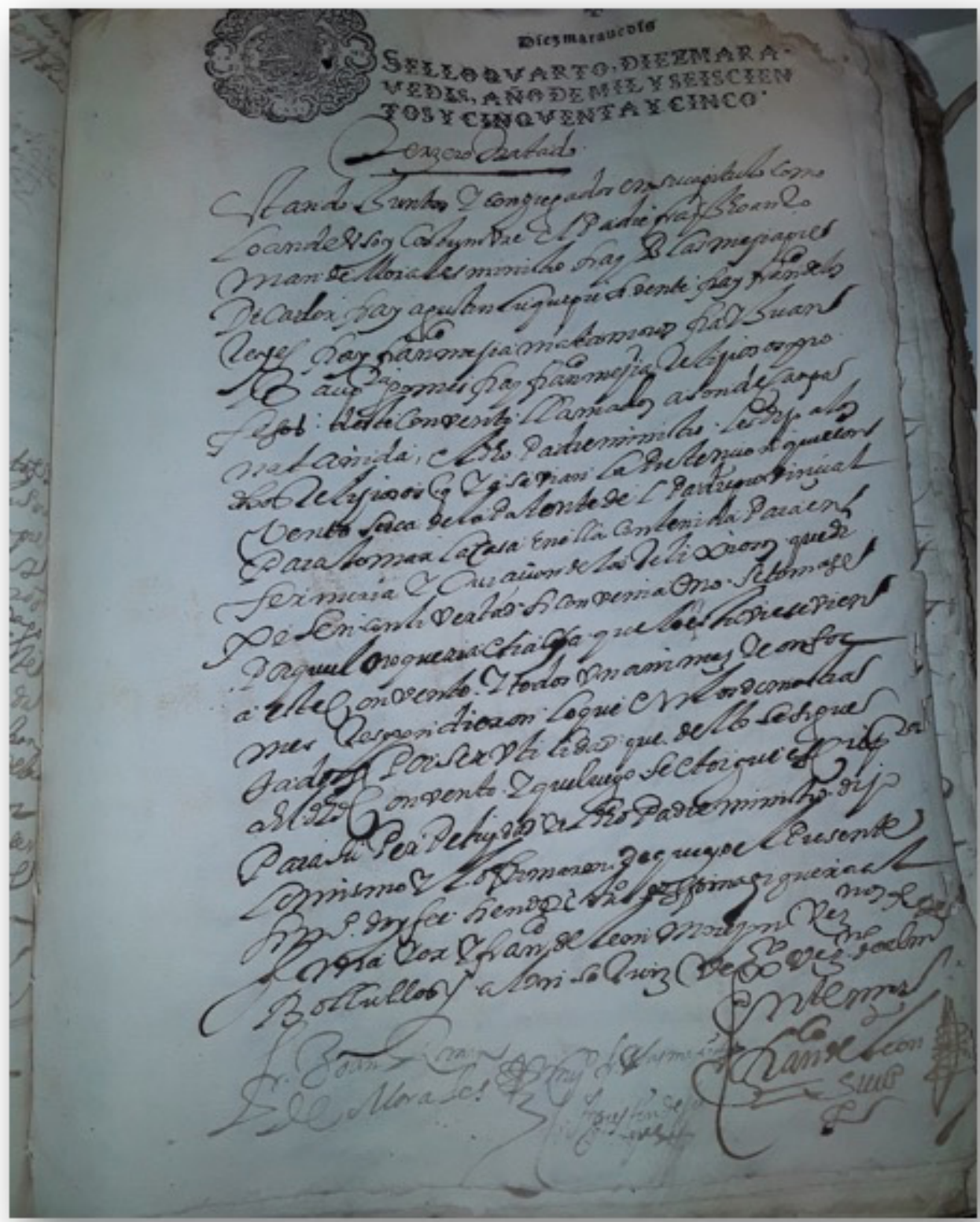

$\mathrm{N}^{\mathrm{o}}$ 4. Por tercera vez, la comunidad de Morañina reunida a capítulo, acepta la limosna de una casa en Almonte, para hacer la enfermería. 


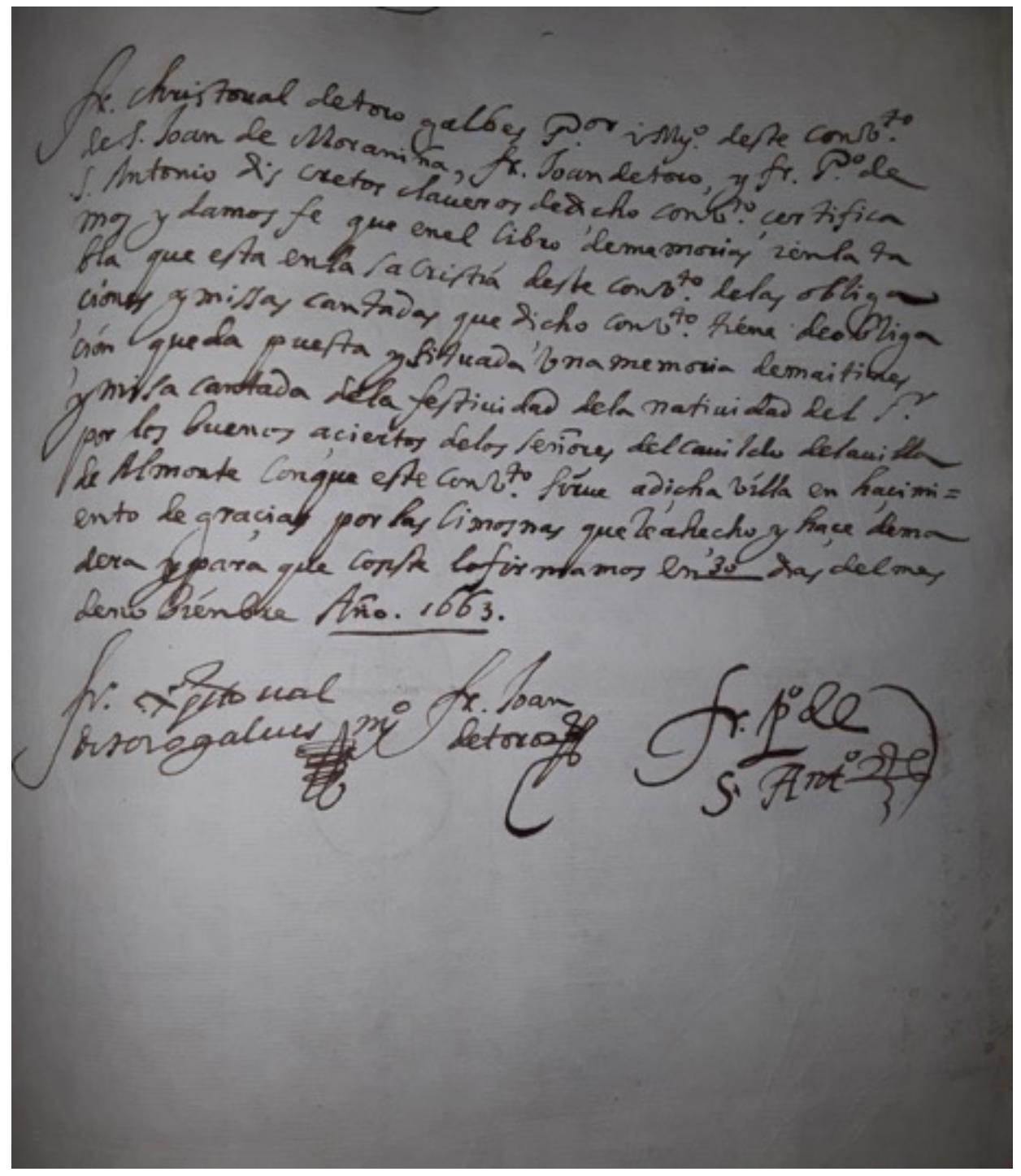

$\mathrm{N}^{\circ}$ 5. Memoria de maitines y misa ofrecida por el ministro de Morañina al Concejo de Almonte, en agradecimiento por los muchos aciertos en la actuación de sus regidores para con la casa convento. 


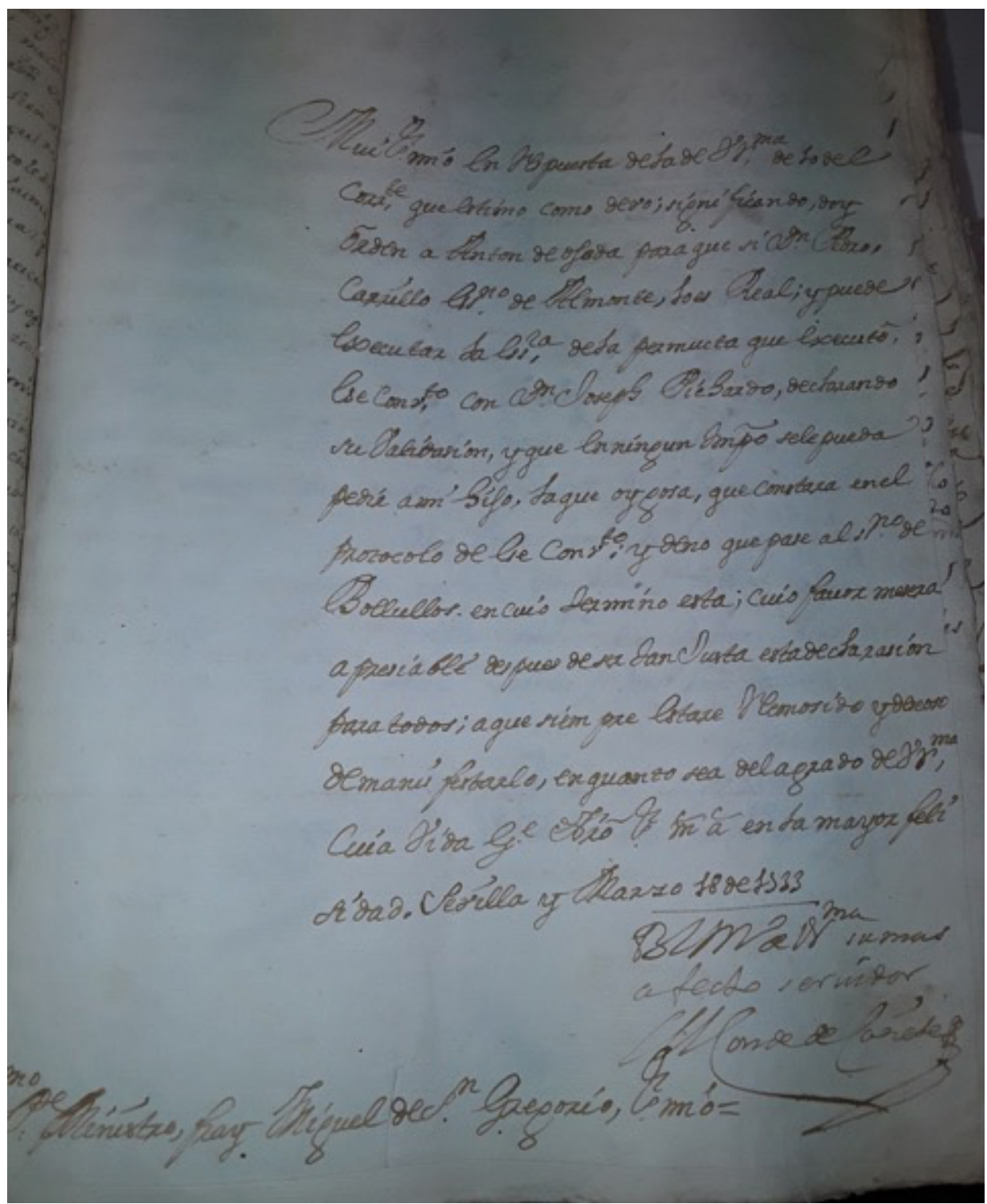

$\mathrm{N}^{o}$ 6. Carta de reconocimiento del Conde de Cañete al ministro del convento de Morañina, después de la permuta de tierra que de mutuo acuerdo, hicieron ambas partes. 


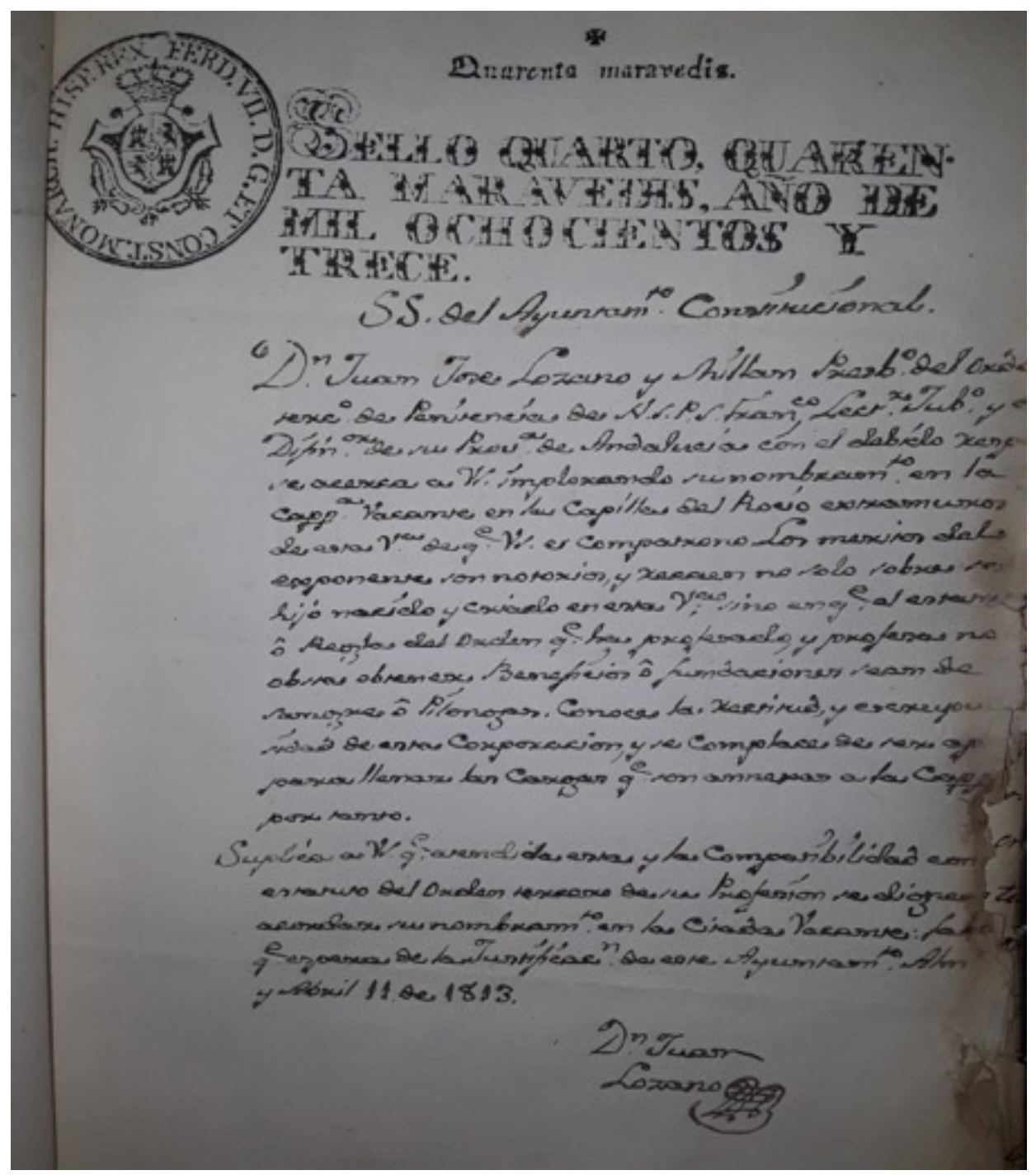

$N^{0}$ 7. Un religioso de la Orden Tercera de Penitencia Franciscana, natural de Almonte, solicita la Capellanía vacante en la ermita de Ntra. Sra. del Rocío. 


\section{Notas.}

1. A(rchivo) $\mathrm{P}$ (rotocolos) $\mathrm{N}$ (otariales) de la $\mathrm{P}$ (alma) del C(ondado), leg. 20, fol. $172 \mathrm{r}$.

2. Ibídem.

3. A(rchivo) $\mathrm{H}$ (ermandad) $\mathrm{M}$ (atriz) de A(lmonte). F(ondo) I(nfante) G(alán), caja 75, libro 33, fol. 61.

4. APNLPC, leg. 20, fol. $420 \mathrm{v}$.

5. C(entro) C(ultural) de la V(illa) de A(lmonte), P(rotocolos) N(otariales), leg. 21, fotograma 10.

6. C. C. V. A., P. N., leg. 21, fotograma 10.

7. AHMA, FIG, caja 75, libro 33, fol. 61.

8. Ibídem.

9. A(rchivo) M(unicipal) de A(lmonte), Acta Capitular de 8/10/1606.

10. AMA, Acta Capitular de 27/09/1607.

11. AMA, Acta Capitular de 29/02/1608.

12. AMA, Acta Capitular de 25/12/1651.

13. AMA, Acta Capitular de 14/01/1657.

14. AMA, Acta Capitular de 18/09/1660.

15. APNLPC, leg. 301, fol. 119.

16. Ibídem, leg. 301, fol. 120.

17. Web Ayuntamiento de Huelva. B(oletín)O(ficial) de la P(rovincia), año 1839, imagen 446.

18. Ibídem, BOP, 1840, imagen 29 y BOP, 1843, imagen 219.

19. APNLPC, leg. 301, fol. 127.

20. Ibídem, leg. 301, fol. 124.

21. Ib., leg. 301, fol. 123.

22. Ib., leg. 332, fol. 6 .

23. AMA, Acta Capitular de 21/08/1658.

24. APNLPC, leg. 121, fol. 153.

25. Ibídem, leg. 121, fol. 157.

26. Ib., leg. 322/2, fol. 39.

27. APNLPC, leg. 322/2, fol. 54.

28. Ibídem, leg. 294/2, s/f.

29. CCVA, PN, leg. 30, fotograma 309.

30. AFCMS, leg. 3.387.

31. Ibídem, leg. 3.387.

32. Ib., leg. 2.224.

33. Ibídem.

34. AMA, Libro de Propios de la villa de Almonte y Patronazgo de Capellanías, s/f.

35. BOPH, 1835, imagen 299.

36. BOPH, año 1838, imagen 58 y 59.

37. BOPH, año 1840, imagen 87. 
BiBLIOGRAFÍA CITADA.

CRUZ DE FUENTES. L. (1908): Documentos de las fundaciones religiosas y benéficas de la villa de Almonte y apuntes para su historia. Huelva, (F. Gálvez), 371 pp. 
